\title{
HISTÓRIA, SUBJETIVIDADE E RESISTÊNCIA: uma conversa entre dois genealogistas
}

\section{History, subjectivity and resistance: a conversation between two genealogists}

\author{
Cezar Prado ${ }^{1}$
}

RESUMO: Este pequeno ensaio visa relacionar noções presentes de forma insistente nos textos de Nietzsche e de Foucault, mas propondo interpretações particulares que podem ser úteis a novas investigações, tanto sobre este autor quanto aquele. O título sugere precisamente uma abordagem do trabalho genealógico de ambos e sua relação com os temas em torno da história, da subjetividade e da resistência, os quais se ligam naturalmente às reflexões sobre o poder tanto em um quanto em outro e abrem espaço para questões muito próprias, embora não exclusivas, ao campo da Ética e da Filosofia Política. Analiso inicialmente como a questão da vida, enquanto critério de valor, se entrelaça nos trabalhos destes autores (de que modo cada um a valoriza, direta ou indiretamente), passando às questões relacionadas à subjetividade e à história e aos modos como o discurso (e o não-discurso) se articula em sua constituição, até concluir com um apanhado geral sobre a ideia de resistência que podemos extrair da íntima conversa entre estes genealogistas.

Palavras-chave: História. Subjetividade. Resistência. Genealogia.

\begin{abstract}
This short essay aims to relate notions present in an insistent way in the texts of Nietzsche and Foucault, but proposing particular interpretations that may be useful to new investigations, as much to this author as to the other. The title suggests precisely an approach to the genealogical work of both and its relationship with the themes around history, subjectivity and resistance, which are naturally linked with their reflections on power and which open a space for very important questions, although not exclusively, to the field of Ethics and Political Philosophy. I initially analyze how the question of life, considered as a value criterion, is intertwined in the works of these authors (how each one values it, directly or indirectly), passing on issues related to subjectivity and history and to the ways in which discourse (and non-discourse) articulates itself in their constitution, until concluding with general remarks on the idea of resistance that we extract from the intimate conversation between these genealogists.
\end{abstract}

Keywords: History. Subjectivity. Resistance. Genealogy.

\footnotetext{
${ }^{1}$ Graduando em Filosofia pela Universidade Federal do Paraná (UFPR) e pesquisador em Filosofia Política. E-mail: cezarprado.m@gmail.com
} 
Desde que escreveu a Segunda Intempestiva (NIETZSCHE, 2007, pp. 57-124), até mesmo antes, Nietzsche apresenta aos seus leitores a preocupação de tornar íntima a relação da história com a vida, ou ainda, de aproximar a história daquilo que constitui o seu oposto, ou seja, de uma percepção a-bistórica que permite aos homens o movimento e a ação, a obstinação na vida a partir do esquecimento. Não se trata aqui, portanto, de opor absolutamente história e esquecimento, mas de precisar as utilidades e as desvantagens de cada um para a vida, estabelecendo um limiar no interior do qual se pode, por um lado, "refletir, comparar, distinguir, tirar conclusões" e, por outro, esquecer o passado para criar saberes sobre si mesmo e o seu entorno, e novos modos de existência a partir destes saberes. O homem que não esquece, diz Nietzsche, é como alguém que sangra até a morte por causa de um pequeno arranhão e, por isso mesmo, seria necessário definir um horizonte para a nossa percepção histórica, dando também espaço além deste horizonte para o a-histórico um voluntário abandono da memória a partir do qual a vida se torna presente.

Em Foucault, descobrimos que a história serve igualmente à vida, mas desta vez por um ângulo distinto ao de Nietzsche, com uma atenção especial dada à política, aos modos pelos quais a vida é submetida por mecanismos políticos de poder e aos pontos frágeis destes mecanismos que nos permitem descobrir veredas para novas relações, novos afetos e novos prazeres. Embora Foucault não dissesse aos outros que era historiador (FOUCAULT, 1984, p. 15), ele fazia esse trabalho e era reconhecido como historiador, carregava em seus livros e em suas aulas toda a poeira dos documentos que examinava na Bibliothèque Nationale e toda a experiência na imersão entre os clássicos, os medievais e os modernos. A utilização que fazia da história para mostrar sistemas de assujeitamento e de controle da vida era evidente não apenas para admiradores como também para declarados inimigos, ao ponto de ser identificado, pela ditadura cívico-militar brasileira que matava quase que indiscriminadamente qualquer um na década de 1970, como um intelectual tentando instalar o comunismo no Brasil - segundo um documento do Ministério da Aeronáutica do dia 24 de novembro de 1975 (HOFFMAN, 2019, p. 10).

A história genealógica, tanto em Foucault quanto em Nietzsche, nos apresenta um sujeito constituído por uma miríade de forças no interior dos espaços que ocupa e a partir da história à qual pertence. Este sujeito que frequentemente assume uma identidade à qual os historiadores tradicionais atribuem uma origem, uma essência e um télos, a história genealógica o torna múltiplo no interior de si mesmo, intrinsecamente, habitado agora não mais por uma unidade representada por uma alma imortal - como dirá Foucault seguindo os aforismos de Nietzsche (FOUCAULT, 1994b, p. 154) -, mas por várias almas mortais, múltiplas e em constante conflito umas com as outras, em relações intrasubjetivas de assujeitamento e de resistência, de articulação e de 
transformação. Lembremos que o homem, para Zaratustra, é uma ponte entre o animal e o alémdo-homem, sendo por isso marcado antes de tudo como uma forma de vida submetida ao devir, uma figura terrena que anunciou a morte de Deus e agora anuncia a morte de si mesmo enquanto essência, o homem enquanto esta figura que desvanece, na orla do mar, como um rosto de areia (FOUCAULT, 1966, p. 398).

O sujeito é compreendido, na genealogia de Foucault, como um elemento social inserido no interior de múltiplas relações de poder que, em cada espaço e em cada momento, em uma instituição qualquer ou no interior de sua própria família, é atravessado por cálculos estratégicos e mecanismos de controle que o dominam produzindo simultaneamente nele certas formas de conduta, a obediência a um conjunto de regras e sentimentos que podem ser utilizados tanto para o aquietamento da indignação quanto para a potencialização de discursos inflamados pela intolerância, pelo ressentimento e pelo ódio. Exemplo dessa análise feita por Foucault sobre o sujeito, sobre a introjeção de comportamentos criados em relações de poder diversas, é a passagem descrita em Vigiar e punir do procedimento de suplício aos mecanismos disciplinares ocorrida entre os séculos XVIII e XIX: a alma ganha uma nova importância política, não mais restrita enquanto objeto de poder aos monastérios e procedimentos de confissão derivados da Idade Média, mas tornando-se elemento de uma nova penalidade que se quer agora incorporal (FOUCAULT, 1975, pp. 16-17). Os exercícios de ascese, negativa e positivamente utilizados durante a Idade Média tanto por monges cristãos quanto por comunidades de contra-condutas na passagem para o Renascimento (FOUCAULT, 2004, pp. 208-211), são no final do século XVII cooptados por estratégias mais amplas de poder e se tornam - com a estruturação de instituições como a escola, o hospital e a prisão - formas inventadas de disciplinamento dos corpos.

O conhecimento, diz Nietzsche, é em si uma invenção, de animais inteligentes nos confins de "um rincão do universo cintilante que se derrama em um sem número de sistemas solares", seres vivos num planeta que após um breve suspiro poderia congelar e fazê-los todos morrer (NIETZSCHE, 2009, pp. 530-541). Este olhar sobre o conhecimento, apresentado neste texto de 1873, acaricia os temas da genealogia que Nietzsche irá desenvolver 14 anos mais tarde, momento em que não apenas os filósofos são submetidos aos seus minuciosos procedimentos de análise e às suas críticas, mas também a própria ciência e a historiografia tradicional que almejam o reconhecimento da objetividade daquilo que produzem - sem qualquer gota de pathos, de instinto ou de arbitrariedade. Os historiadores que querem descrever a história como se estivessem pairando sobre ela, em sua plena exterioridade, se encontram afastados da percepção genealógica da história; enquanto eles buscam, apoiados sobre uma espécie de doutrina platônica das reminiscências, identificar o fio da história que lhes permitiria observar sua origem, sua essência e o seu fim, como 
se este fio fosse algo tão antigo quanto a própria humanidade, o genealogista reconhece os desvios de todo começo e as imperfeições de toda ideia humana, até mesmo das ideias que surgem de sua própria cabeça enquanto genealogista. "Imperfeições" não em um sentido axiológico, moralista, mas no sentido perceptivo pelo qual o mundo, a sociedade e os outros são por cada um de nós percebidos. Nietzsche chega a dizer no Prólogo à Genealogia da moral: "Nós, homens do conhecimento, não nos conhecemos; de nós mesmos somos desconhecidos" (NIETZSCHE, 2012, p. 7).

Uma considerável parte da genealogia elaborada por Foucault expressa uma intenção de simples descrição dos fenômenos históricos denunciada por Nietzsche ${ }^{2}$. Foucault diz que o papel do intelectual não é dar palpite sobre o que se deve fazer a respeito de questões políticas, que o intelectual deve antes assumir uma posição estritamente específica e fornecer instrumentos para que os outros, por eles mesmos, possam atuar politicamente (FOUCAULT, 1994b, pp. 306-310; 1994c, pp. 154-158), implicando naquilo que ele faz "um engajamento pessoal, físico e real, colocando os problemas em termos concretos, precisos, definidos no interior de uma dada situação" (FOUCAULT, 1994d, p. 80). Foucault estaria aqui se privando, à diferença de Nietzsche, de elementos normativos que poderia propor enquanto intelectual, optando pela utilização do aparato teórico por ele elaborado em suas lutas pessoais tal como no Grupo de Informação sobre as Prisões ou em suas manifestações públicas contra o autoritarismo no Brasil de Ernesto Geisel (HOFFMAN, 2019, p. 6) e na Espanha de Francisco Franco (RODRIGUES \& DIAS, 2019, pp. 9-10).

Importante para nós é perceber como o trabalho genealógico de Foucault, sendo pouco ou nada normativo, propõe constantemente a criação de novas subjetividades a partir de relações existentes na própria malha das relações de poder. Não apenas criar novas relações, mas também encontrar tipos de relações já existentes, em aproximação com a diferença e com sempre novas possibilidades de transformação daquilo que já existe. É nesse sentido que ele historiciza o surgimento, no século XVIII, do que vai chamar de dispositivo de sexualidade, dispositivo que objetiva o assujeitamento dos corpos e a limitação das formas de prazer através de mecanismos ligados à histerização do corpo da mulher, à pedagogização do sexo da criança, ao controle das condutas de procriação e à psiquiatrização do prazer perverso (FOUCAULT, 1976, p. 137-139). Partindo desse trabalho de localização das limitações que envolvem o corpo e o uso dos prazeres, Foucault mostra como uma prática sexual como o sadomasoquismo pode ser compreendida não em termos normalizadores e morais de perversão, não como uma relação na qual um sofre e o outro infringe

\footnotetext{
${ }^{2}$ Nietzsche escreve: "Ou quem sabe a moderna historiografia demonstrasse uma maior certeza de vida, certeza de ideal? Sua pretensão mais nobre está em ser espelho; ela rejeita qualquer teleologia; nada mais deseja 'provar'; desdenha fazer de juiz, vendo nisto seu bom gosto - ela não afirma, e tampouco nega, ela constata, 'descreve'... Tudo isso é ascético em alto grau; ao mesmo tempo, que não haja engano, é niilista em grau ainda mais elevado!", in Genealogia da moral, III, \26, op. cit., 2012.
} 
sofrimento, mas sim como um jogo onde "um pode ganhar e o outro perder", sem que a relação perca suas intensidades singulares e os seus prazeres inventivos (FOUCAULT, 1994d, p. 331).

Arrisco dizer que Foucault se utiliza de Nietzsche - o filósofo defensor da aristocracia, do eugenismo e de inúmeros discursos machistas -, assim como Marx se utiliza de Ricardo, o liberal que nas primeiras páginas d'O capital é descrito tanto como o representante da economia política burguesa quanto o criador de uma teoria que "serve, excepcionalmente, como arma de ataque contra a [própria] economia burguesa" (MARX, 2019, p. 85). Sabemos que Marx se utiliza das teorias do valor de Ricardo para suas próprias elaborações teóricas (HARVEY, 2013, p. 33), efetuando modificações sutis que terão, na composição geral da obra e como efeito de práxis, um efeito bastante considerável. No mesmo sentido, Foucault se utiliza da teoria das forças de Nietzsche não para mostrar que o doente é um "parasita da sociedade" ou que caberia "aos médicos decidir quem deve viver e quem deve morrer" (NIETZSCHE, 2012, Incursões de um extemporâneo, \$36), mas para mostrar que a própria utilização discursiva de um conceito como "doente mental" ou a própria autoridade que se confere ao médico sobre a vida de um indivíduo fazem parte de sistemas coercitivos de poder contra os quais não somente podemos resistir, como também podemos transformar a partir deste ato de resistência. A resistência aparece aqui como afirmação da luta, como em Nietzsche, mas também como intransigência diante das tentativas de normalização unilateral e definição de valores superiores em nome de um homem que fosse superior ${ }^{3}$.

Podemos elencar aqui, provisoriamente, alguns elementos que definiriam a resistência a partir destes problemas colocados, tanto em Nietzsche quanto em Foucault, em torno da história e da subjetividade: (1) a resistência se apresenta em relações de poder, sempre compreendidas em seu sentido mais amplo como relações que atravessam todo o tecido social e produzem novas condutas, novos afetos e novos aparatos de dominação; (2) a resistência é sobretudo corporal, ela emerge no ato de expor o próprio corpo em risco, mesmo quando o conflito se encontra num plano meramente teórico e discursivo, e isso pelo simples fato de que mesmo o discurso mais ingênuo tem como efeito mais considerável a sua materialização no mundo, nos corpos e nas vidas de cada um e de cada uma; (3) a resistência é essencialmente inventiva, ela cria no próprio movimento de oposição que representa, exigindo uma constante alteração das táticas às quais se relaciona para não ser totalmente aniquilada, para não ser eliminada por um poder que visa se impor em uma relação totalizante que levaria à sua própria consumação; (4) a resistência pode ser reproduzida em suas táticas particulares em contextos históricos que permitem essa reprodução,

\footnotetext{
${ }^{3}$ Conferir, sobre o eugenismo em Nietzsche, o excepcional artigo de Emmanuel Salanskis intitulado "Sobre o eugenismo e sua justificação maquiaveliana em Nietzsche”, in Cadernos Nietzssche, n. 32, 2013.
} 
ela não pode ser completamente replicada porque se define precisamente por sua inventividade, mas nos usos da história onde aparece podemos retomá-la e aplicar as táticas utilizadas (e.g. por essa greve de trabalhadores ou por aquela revolta de negros escravizados) em nossa experiência de luta contemporânea; por fim, (5) a resistência não está em relação de oposição ao prazer, ela pode certamente se vincular a sentimentos penosos e dolorosos, mas ela pode igualmente se expressar como uma potência que dá espaço a inúmeros prazeres (a) pela relação que se estabelece com outros com os quais se resiste, (b) pela relação amistosa que se pode estabelecer com o próprio polo da relação de poder (e.g. as práticas BDSM), e (c) pelo fato de ela colocar o sujeito numa nova posição da relação, alterando positivamente o jogo dos poderes e produzindo um movimento singular frente ao outro e frente à história.

\section{REFERENCIAS}

FOUCAULT, Michel. Dits et écrits II, Éditions Gallimard, 1994b.

FOUCAULT, Michel . Dits et écrits III, Éditions Gallimard, 1994c.

FOUCAULT, Michel . Dits et écrits IV, Éditions Gallimard, 1994d.

FOUCAULT, Michel. Histoire de la sexualité I : La volonté de savoir. Éditions Gallimard, 1976.

FOUCAULT, Michel. Histoire de la sexualité II : L'usage des plaisirs. Éditions Gallimard, 1984.

FOUCAULT, Michel .Les mots et les choses. Éditions Gallimard, 1966.

FOUCAULT, Michel .Sécurité, territoire, population. Seuil/Gallimard, 2004.

FOUCAULT, Michel. Surveiller et punir. Éditions Gallimard, 1975.

HARVEY, David. Para entender O capital. Trad. Rubens Enderle, Boitempo Editorial, 2013.

HOFFMAN, Marcelo. "From public silence to public protest", in Foucault and the politics of resistance in Brazil, U.S. Litograph Inc., 2019.

MARX, Karl. O capital - Livro 1. Trad. Rubens Enderle, Boitempo Editorial, 2019.

NIETZSCHE, Friedrich. Crepúsculo dos ídolos. Trad. Renato Zwick, L\&PM, 2012.

NIETZSCHE, Friedrich. "On the uses and disadvantages of history for life", in Untimely meditations, translated by R. J. Hollingdale, Cambridge University Press, 2007, pp. 57-124.

NIETZSCHE, Friedrich. "Sobre a verdade e a mentira em sentido extramoral", in Antologia de textos filosóficos. Trad. Rubens Torres Filho, SEED, 2009, pp. 530-541. 
RODRIGUES, Heliana; DIAS, Rosimeri. "The tiny brazilian press as resistance", in Foucault and the politics of resistance in Brazil, U.S. Litograph Inc., 2019.

SALANSKIS, Emmanuel. "Sobre o eugenismo e sua justificação maquiaveliana em Nietzsche", in Cadernos Nietzsche, n. 32, 2013. 